\title{
Review
}

\section{Neurogenic stress cardiomyopathy following aneurysmal subarachnoid haemorrhage: a literature review}

\author{
Lukas Piliponis ${ }^{a}{ }^{*}$, Gintarè Neverauskaitè-Piliponienè ${ }^{a}$, \\ Monika Kazlauskaitė a , Pavel Kačnov ${ }^{a, c}$, Sigita Glaveckaitè ${ }^{\text {a,b }}$, \\ Jūratė Barysienè ${ }^{\mathrm{a}, \mathrm{b}}$, Saulius Ročka ${ }^{\mathrm{a}, \mathrm{c}}$ \\ a Vilnius University, Faculty of Medicine, Vilnius, Lithuania \\ $\mathrm{b}$ Clinic of Cardiovascular diseases, Institute of Clinical Medicine, Vilnius University Faculty of Medicine, Vilnius, Lithuania \\ c Clinic of Neurology and Neurosurgery, Institute of Clinical Medicine, Vilnius University Faculty of Medicine, Vilnius, Lithuania
}

Received 16 April 2019; accepted 25 September 2019

\begin{abstract}
Summary
Neurogenic stress cardiomyopathy (NSC) is defined as transient cardiac dysfunction occurring after primary brain injury, such as aneurysmal subarachnoid haemorrhage, and characterised by left ventricular systolic dysfunction with reduced ejection fraction and abnormalities of regional wall motion. It may also be suspected if elevated levels of cardiac biomarkers and ECG abnormalities are present. It is a reversible condition with favourable long-term prognosis if diagnosed and treated timely, however, NSC is associated with higher rates of early mortality and complications, including pulmonary oedema, cardiogenic shock, delayed cerebral ischaemia. Early diagnosis of the NSC is important in order to prevent these complications and reduce mortality. Management of the NSC is complicated and a multidisciplinary approach is usually required.
\end{abstract}

Seminars in Cardiovascular Medicine 2019; 25:44-52

Keywords: aneurysmal subarachnoid haemorrhage, neurogenic stress cardiomyopathy, Takotsubo-like cardiomyopathy, neurogenic stunned myocardium

\section{Introduction}

Aneurysmal subarachnoid haemorrhage (aSAH) is a type of haemorrhagic stroke which occurs due to a ruptured intracranial aneurysm [1]. aSAH has an incidence of 6.3 per 100000 persons per year in Europe and accounts for 5\% of all strokes. High mortality rates, poor functional outcomes, high disease-specific burden these are the terms associated with aSAH $[2,3]$. While the mentioned issues are widely recognized, aSAH may also cause cardiac dysfunction: ECG changes, cardiac arrhythmias, elevated cardiac biomarkers, left ventricular dysfunction [4]. Pathophysiology is mostly explained by massive catecholamine release, resulting in myocardial injury [5]. Cardiac abnormalities can occur alone or be a part of the disease called neurogenic

\footnotetext{
* Corresponding address: Lukas Piliponis, M. K. Čiurlionio g. 21/27, LT-03101, Vilnius

E-mail: luke.piliponis@gmail.com.
}

stunned myocardium or neurogenic stress cardiomyopathy (NSC), some articles even use the name of Takotsubo-like cardiomyopathy [6]. It is unclear if we can use NSC as a synonym of Takotsubo cardiomyopathy or these definitions are different and should not be mixed. Takotsubo cardiomyopathy, which is transient and typically precipitated by acute emotional stress, is also known as "stress cardiomyopathy" or "broken-heart syndrome". Takotsubo cardiomyopathy mimics acute coronary syndrome and is accompanied by reversible left ventricular apical ballooning in the absence of angiographically significant coronary artery stenosis [7]. Both diseases are followed by left ventricular (LV) systolic dysfunction, changes on ECG and release of cardiac biomarkers [8]. Takotsubo cardiomyopathy usually occurs after an emotional stress event while NSC occurs after a primary neurological event, e.g. aSAH, and manifests with chest pain and clinical signs of heart failure with neurological damage [9]. Studies show that NSC is related to higher in-hospital mortality after aSAH [10]. For- 
tunately, NSC can be reversed if diagnosed on time, this is why it is important to review the data on the matter. In this review, we will focus on pathophysiology, clinical features, functional outcomes, and management of aSAH induced cardiac dysfunction.

\section{Methods}

MEDLINE database and PubMed search system were used for this review. The following words and phrases, as "neurogenic stress cardiomyopathy", "takotsubo-like cardiomyopathy", "subarachnoid haemorrhage", "stroke", "cardiovascular", "cerebrovascular diseases" were used for the search. We searched and evaluated review studies, observational and randomised clinical trials, case reports, published in English until April 2019.

\section{Results}

\section{Subarachnoid haemorrhage and neurogenic stress cardiomyopathy}

Acute central nervous system lesions can induce sudden cardiac dysfunction for patients with no prior underlying cardiovascular disease and contribute to higher in-hospital mortality rates and poor outcomes [11-14]. Particularly, spontaneous acute aSAH is known to trigger abnormal heart conduction manifestations [15]. The relationship of these ECG abnormalities and cardiac rhythm disturbances with NSC was found out only later on [6]. The currently reported prevalence of NSC among aSAH patients range from $2.2 \%$ to $17 \%[12,16-20]$. Brain injury (autonomous nervous system damage in supramedullar or medullar regions) during an acute neurological event is the main factor for the development of subsequent cardiac manifestations. Insular cortex injury or hypothalamic damage due to increased intracranial pressure accompanied by direct extravasated blood pressure to hypothalamus can initiate a catecholamine release overdrive $[11,21]$.

\section{Catecholamine outburst and cardiotoxicity}

The most acceptable current evidence-based theory of NSC heavily relies on catecholamineinduced myocardial injury [21-23]. A large amount of locally excreted catecholamines bind to cardiac adrenoreceptors and induces cardiomyocytolysis because of calcium overflow into cells, that, in turn, causes specific cell injury, including contraction band necrosis (due to reperfusion in hyper concentration condition) [23,24], monomorphonuclear cell infiltration, and the histopathologic picture, that is quite distinct from coagulation necrosis in acute myocardial infarction [24]. Myocardium ischaemic alteration is observable only hours to days after the acute coronary event when cardiac cell death occurs $[25,26]$. In comparison, NSC myocytolysis takes place shortly after the catecholamine rush and becomes noticeable 5 minutes after the onset of aSAH $[6,27]$. Catecholamine plasma serum concentration peak correlates with the level of heart injury biomarkers: i.e. peak elevation of Troponin $\mathrm{T}$ and CK-MB $[6,27]$. Secreted local acting catecholamines, rather than circulatory, are responsible for myocardial injury in NSC [28]. During the intracranial injury, local catecholamines are released from cervical sympathetic ganglia through cardiac nerves and sympathetic plexus nerve endings. Sympathetic heart denervation as demonstrated in an experimental baboon model by Novitzky et al. can ultimately abolish heart response to brain lesions [28]. Following the same logic heart recipient patients unfortunate enough to experience aSAH, should evade NSC because of heart denervation effect that they received during transplant surgery. Catecholamine cardiotoxicity is highly involved in the pathophysiologic mechanisms of NSC.

\section{Similarities with Takotsubo cardiomyopathy}

A similar pathophysiology mechanism is responsible for Takotsubo cardiomyopathy [7] but NSC and Takotsubo differ by primary cause, the first one develops due to a neurological event and the second one takes place under emotional stress [9]. There is no consensus on the matter. Some authors suggest that this is the same disease with the same outcomes, others classify Takotsubo as primary stress cardiomyopathy and NSC - as a secondary stress cardiomyopathy [7], and others declare these as two distinct conditions. Nevertheless, there is a lack of studies that would actually compare these two patient groups and present the answer. One study by Ancona et al. reported clinical differences between Takotsubo and NSC. A study shows that NSC clinical signs are more commonly present as heart failure, rather than acute coronary syndrome as it is in Takotsubo cardiomyopathy. Furthermore, patients with NSC have a lower level of cardiac biomarkers and, most importantly, regional wall motion abnormalities (RWMA) are more present in the basal segment rather than apical, as it is in Takotsubo cardiomyopathy [8].

\section{ECG abnormalities and rhythm disorders}

The development of cardiac complications after aSAH can result in ECG changes as well as cardiac arrhythmias $[8,29]$. ECG changes after 
aSAH can be found in up to $98 \%$ of patients $[15,30,31]$, including ST-segment and T-wave abnormality, the presence of $\mathrm{U}$ wave, $\mathrm{P}$ wave abnormalities, and prolonged QTc interval that are common and often seen early after haemorrhaging into subarachnoid space [32]. According to Ahmadian et al. the most common ECG abnormalities for patients with NSC are T wave inversion $-17.2 \%$, ST interval depression $-13.8 \%$ and prolonged QT interval - 10.3\% [33]. The prevalence of heart rhythm disorders ranges from 50\% to $90 \%$ of patients $[34,35]$. The data concerning the prevalence differ depending on the study. The most common disorders include sinus tachycardia, sinus bradycardia, atrial fibrillation and atrioventricular block [34-36]. Although the majority of the occurring arrhythmias are mostly benign, up to $5 \%$ can be clinically significant and life-threatening [37]. Usually, ventricular or atrial fibrillation may develop within the first 2 days after aSAH [38]. These ECG changes and rhythm disturbances after aneurysmal subarachnoid bleed are related to a poor functional outcome, longer hospitalisation period and higher in-hospital mortality rate [39]. These ECG findings are not specific for this cardiomyopathy, and it is important to take into account clinical case presentation and the data of diagnostic modalities, in order to establish the diagnosis of NSC. Nevertheless, we should keep in mind and expect heart electrophysiological changes since NSC patients are more prone to develop them after a cerebral aneurysm rupture [30].

\section{Cardiac markers in blood serum}

Troponin (Tn) consists of three subunits - I, T and $\mathrm{C}$, that are a part of skeletal and cardiac muscle filaments. For nearly 25 years, two of these troponin isoforms (I and T) are being used in every day clinical practice to diagnose diseases involving cardiomyocyte death. Cardiac troponin I (cTnI) and troponin $\mathrm{T}(\mathrm{TnT})$ are useful in diagnosing NSC and predicting outcomes for patients after aSAH [40]. During initial 24-48 hours after aSAH, cTnI levels can peak above the limit $(>0.1 \mathrm{ng} / \mathrm{ml})$. This clinical phenomenon is common in $20-40 \%$ of aSAH patients and most of them do not have a coronary artery disease (CAD) [41]. cTnI serum concentration elevation has an important prognostic value for in-hospital mortality, hospital stay length, echocardiographic abnormalities and prediction of NSC. The patients with very high cTnI $(>1.0 \mathrm{ng} / \mathrm{ml})$ levels have higher in-hospital mortality rates that reaches up to $40 \%$ in comparison with $11 \%$ for patients with mild or low cTnI levels after aSAH [42]. A prospective study by Tanabe M. et al. found that patients with high levels of cTnI $(>1.31 \mathrm{ng} / \mathrm{ml})$ were more associated with prolonged hospital stay than those with mild or low levels of cTnI (14 vs 11 days respectively). Moreover, the study established that high levels of cTnI could predict abnormal heart wall motion in echocardiography with a $76 \%$ sensitivity and $91 \%$ specificity [43]. Abnormal regional wall motion is one of the cardiac abnormalities occurring in NSC, this means that cTnI, in a way, can help suspect RWMA. Furthermore, elevated cTnI levels predict poor functional outcomes after aSAH alike [44]. Another troponin isomere - hsTnT (high sensitivity troponin T) enables to detect NSC, also. A study by Oras et al. established that hsTnT peaked over $89 \mathrm{ng} / \mathrm{l}$ within 48 hours after the initial subarachnoid bleed, thus predicting NSC (sensitivity - 100\%, specificity - 79\%). The same study discovered that N-terminal pro B type natriuretic peptide (NT pro-BNP) could even be a better early marker for NSC [45]. NT pro-BNP is a heart marker, used in clinical practice for evaluation of heart failure, caused by left ventricular dysfunction [46]. In aSAH patients, the early increase of NT pro-BNP levels above $2.615 \mathrm{ng} / \mathrm{l}$ is correlated with the onset of pulmonary oedema, myocardial necrosis, systolic and diastolic dysfunction of the left ventricle, therefore, NT pro-BNP can be used as a promising NSC biomarker [47]. Both markers can be used to predict heart complications and outcomes after aneurysmal subarachnoid bleeding. Early biochemical cardiac marker increase can help suspect NSC and allow practitioners to start treatment timely.

\section{Echocardiographic left ventricular dysfunction}

NSC occurs as transient left ventricular (LV) systolic dysfunction early after aSAH and is described as an abnormal myocardium wall motion and reduced global ejection fraction (EF) [48]. RWMA may be present from $10 \%$ to $36 \%$ of cases in patients with NSC. Usually, LV systolic dysfunction impairs the basal and midventricular segments of the anterior and anteroseptal walls $[49,50]$. RWMA is associated with higher mortality, with a relative risk of 1.9 [39]. As reported by Sugimoto et al. the reduction of $\mathrm{LV}$ ejection fraction (below 50\%) was observed in up to $62 \%$ of patients. However, the average LV EF of all patients was approximately $40 \%$ [49, 51]. A study by Ahmadian et al. reported similar prevalence: $55.7 \%$ of patients had LV EF between $40-60 \%$, and only $6.6 \%$ of patients had LV EF lower than $40 \%$ [33]. These two features, causing LV systolic dysfunction, may be isolated or present both. LV systolic dysfunction can result in systemic complications, pulmonary oedema, cardiogenic shock and it places patients at risk for 


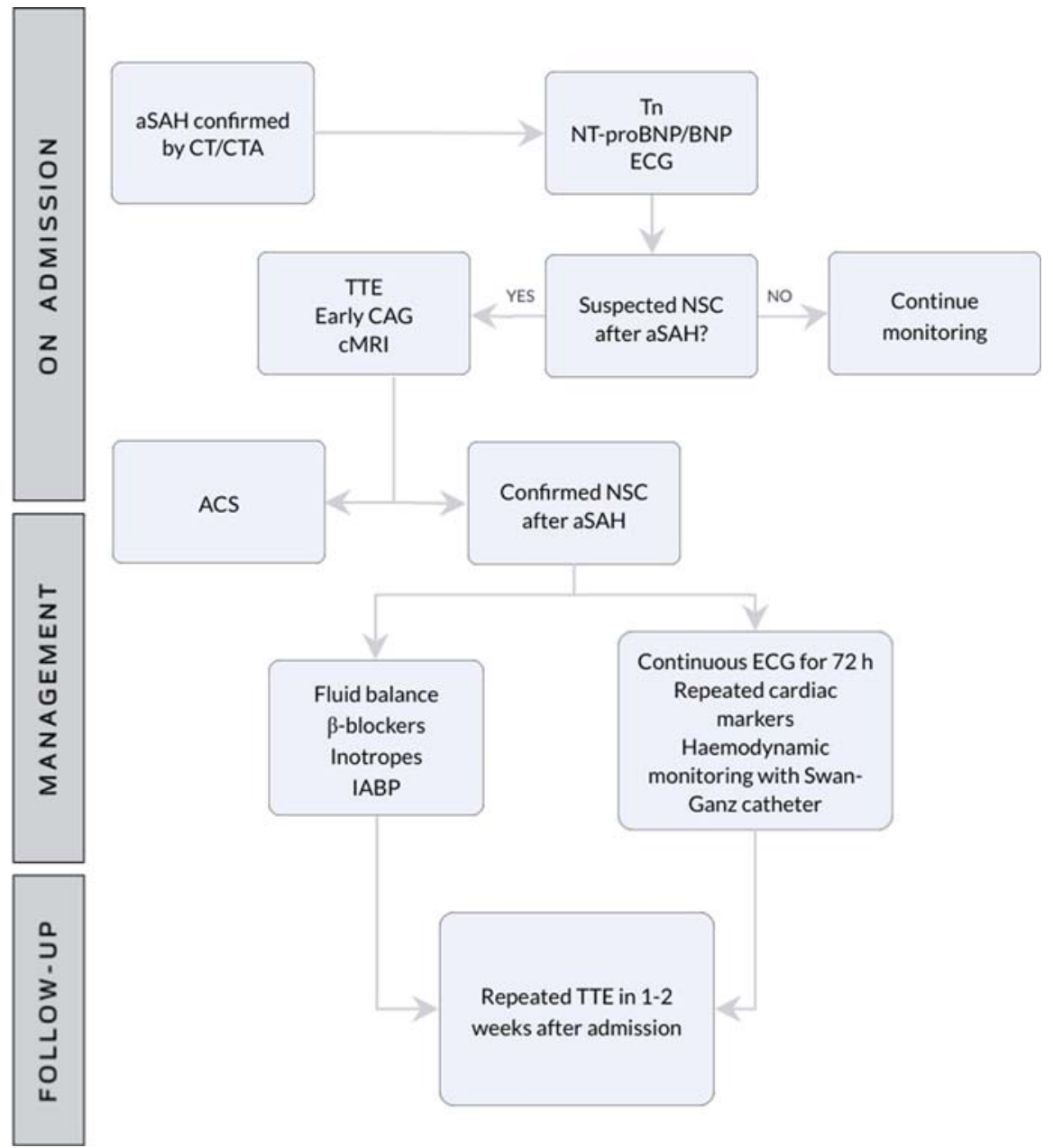

Figure 1. A suggested diagnostic and treatment approach to patients with neurogenic stress cardiomyopathy after aneurysmal subarachnoid hemorrhage. aSAH - aneurysmal subarachnoid hemorrhage; CT - computed tomography; CTA - computed tomography angiography; Tn - troponin; NT-proBNP - N-terminal pro B type natriuretic peptide; BNP - B type natriuretic peptide; ECG - electrocardiogram; TTE - transthoracic echocardiogram; CAG - coronary angiography; cMRI - cardiac magnetic resonance imaging; NSC - neurogenic stress cardiomyopathy; ACS - acute coronary syndrome; IABP - intra-aortic balloon pump.

cerebral ischaemia, putting NSC as a significant risk factor for mortality in aSAH patients. NSC accompanying acute brain injury is responsible for high mortality during hospitalisation (NSC $46.9 \%$ vs non-NSC $11.2 \%$ ) [19]. However, reduced LV EF and RWMA are reversible and improvement of these echocardiographic findings are reported after a few follow-up weeks in NSC patient group $[18,48]$. Up to $66 \%$ of the NSC patients have a full or partial recovery of LV systolic function [48].

\section{Diagnostic approach}

As it was mentioned previously, elevated levels of troponin, serum cardiac natriuretic peptides, ECG abnormalities, and echocardiographic changes might presume NSC after aSAH diagnosis. Cardiac markers and ECG should be evaluated on admission and echocardiographic evaluation should follow if cardiac markers are elevated or ECG abnormalities are observed [52]. Additionally, acute coronary syndrome should be ruled out, since elevated troponin levels and signs of myocardial ischaemia are not NSC specific $[12$,

Figure 2. Neurogenic stress cardiomyopathy clinical example. A. Head computed tomography image with evidence of subarachnoid haemorrhage in cerebral basal cisterns. B. Head computed tomography angiography: right middle cerebral artery ruptured gigantic aneurysm causing subarachnoid haemorrhage. C. Electrocardiography: sinus rhythm, long QTc interval (454 ms). D and E. Transthoracic echocardiography: four chamber view at the end-diastole (D) and end-systole (E) showing hypokinesis of basal partly midventricular segments of the left ventricle (LV), the apex and apical segments of LV are hyperkinetic. F. Invasive coronary angiography: left coronary artery without any changes. G. Invasive coronary angiography: left coronary artery without any changes. 

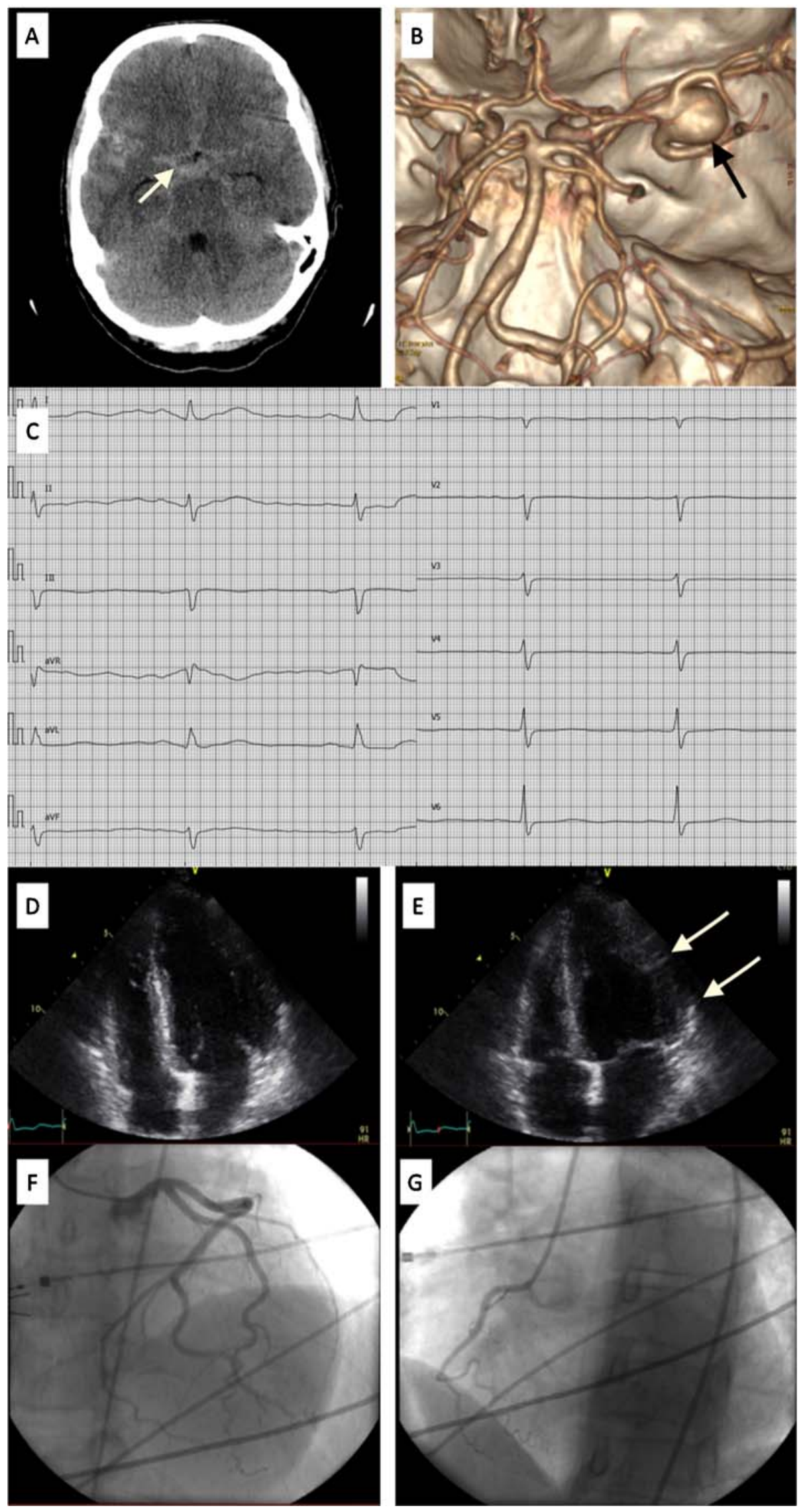
41]. Although, it is important to note that lower troponin and higher BNP blood serum levels are more frequent in NSC after subarachnoid haemorrhaging distinguishing them from acute coronary syndrome (ACS) patients [53]. In order to differentiate, early coronary angiography or cardiac magnetic resonance imaging (cMRI) might be the best option but it should be considered responsibly since coronary angiography is not recommended after aSAH routinely [12,54].

The most common major complications of NSC are acute heart failure, accompanied by cardiogenic shock, ischaemic stroke, arrhythmias, myocardium apical thrombosis and ventricular rupture [54,55]. Since ECG changes often develop within the first three days after aSAH, continuous ECG monitoring should be provided for at least 72 hours after admission $[48,56]$. Cardiac markers (BNP and Tn) should be repeated. BNP serum concentration increases soon after a subarachnoid bleed and returns to baseline within 2 weeks [23]. Elevated troponin levels were noticed in the first 72 hours likewise [57]. Continuous haemodynamic monitoring with a Swan-Ganz catheter should be considered in order to achieve appropriate measurement of central venous pressure [58]. In case NSC is suspected, a higher level of intensive care management by an interventional neurologist, a neurosurgeon, a cardiologist, and an intensive care practitioner should be carried out. Summary of diagnostic approach is demonstrated in Fig. 1 and typical case presentation is showed in Fig. 2.

\section{Neurogenic stress cardiomyopathy treatment}

While haemodynamic augmentation, described as triple- $\mathrm{H}$ therapy (treatment of hypertension, hypervolemia and haemodilution), has been a mainstay in the management of ischaemic cerebral conditions. Fluid balance, $\beta$-blockers, inotropes and an intra-aortic balloon pump (IABP) are used for the treatment of NSC after aSAH [52, 58]. It is important to optimise cardiac output, maintain euvolemia and avoid hypotension in order to prevent complications including delayed cerebral ischaemia [19].

$\beta$-blockers are considered to lower the risk of developing NSC by preventing the elevation of cardiac enzymes, development of arrhythmias and ECG abnormalities $[5,59,60]$. In the acute phase, $\beta$-blockers may be useful to reduce basal hypercontractility and increase cardiac filling, additionally lowering cardiac rupture risk $[61,62]$. Despite this, recurrent NSC developed in 32.5$50.9 \%$ of the patients using $\beta$-blockers, but cardiac involvement was minor comparing to the first event. This means $\beta$-blockers are not effective in prevention of repetitive NSC but these medi- cations may mitigate the clinical manifestations $[54,63]$. There is some data that combined use of angiotensin converting enzyme (ACE) inhibitors and $\beta$-blockers tends to be an effective therapy preventing from recurrence of NSC [7].

Haemodynamic stability that is related to adequate cerebral perfusion and prevention for delayed cerebral ischaemia, might be maintained by means of vasopressors or inotropes. For example, using such vasopressor as phenylephrine, an $\alpha_{1}$-adrenergic receptor selective agonist, may be an option for hypotension treatment in patients with aSAH who do not tolerate fluid management or $\beta$-blockers resulting in an increased afterload and LV cavity size [7]. In the presence of LV dysfunction, haemodynamic instability and cardiogenic shock, such inotropes as dobutamine or milrinone might optimize the mean arterial pressure and cerebral perfusion pressure [56]. If dobutamine and milrinone are ineffective, levosimendan in comparison to $\beta$-agonist or phosphodiesterase inhibitor action on circulatory system may increase heart contractility and induce a vasodilatatory effect, resulting in improvement of organ hypoperfusion [64].

In patients with left ventricular outflow tract obstruction manifesting as hypotension, intravenous inotropes should be avoided and treatment using $\beta$-blockade and IABP should be then preferred $[65,55]$. Difficulties to achieve the blood pressure goals for haemodynamic augmentation because of low cardiac output are reported. In this situation, increased doses of inotropes and vasopressors could worsen hypotension and can determine secondary brain injury [51]. When high doses of vasopressors and inotropes are ineffective, the management using IABP may be indicated [56]. Usually, while using IABP, the demand for vasopressors decreases for mean of 50\% within the first or the second day after initiation. Duration of IABP use ranges from 1 to 7 days (mean 4 days), resulting in normalized cardiac enzymes and function [66]. Despite high morbidity and mortality, NSC management is mainly supportive and symptomatic, based on the treatment of life-threatening events and there are no available clinical management and specific treatment recommendations so far [67]. Summary of possible treatment is presented in Fig. 1.

\section{Follow-up of left ventricular dysfunction}

Recurrence of cardiomyopathy has been observed within the first year (average of 3 months) and no deaths after discharge were due to cardiac causes, suggesting that comorbidities are main predictors of mortality in these patients [68]. However, it is still important to follow-up the LV systolic function. Steady LV EF and RWMA im- 
provement was observed since the $1^{\text {st }}$ to the $3^{\text {rd }}$ week after the onset of aSAH $[63,69]$. Usually, the function of LV improves in a week. Therefore, it is recommended to repeat echocardiogram after 1 or 2 weeks after admission and perform the examination again, after $4-5$ weeks following clinical recovery $[48,53,56,70]$.

\section{Conclusions}

Catecholamine outburst after aSAH causes cardiac abnormalities. These include ECG changes, life-threatening arrhythmias, elevated cTn and NT pro-BNP levels, which can appear and predict NSC and its prognosis. Subarachnoid bleeding can also cause LV systolic dysfunction which can confirm the diagnosis of NSC. Management of the NSC is difficult and personalised treatment by a multidisciplinary team is required. More studies are needed for a better understanding and achieving universal NSC diagnostic algorithm as well as treatment options in order to prevent complications and reduce mortality.

\section{References}

[1] Dority JS, Oldham JS. Subarachnoid hemorrhage: an update. Anesthesiol Clin 2016;34(3):577-600.

[2] Etminan N, Chang HS, Hackenberg K, de Rooij NK, Vergouwen MDI, Rinkel GJE, Algra A. Worldwide incidence of aneurysmal subarachnoid hemorrhage according to region, time period, blood pressure, and smoking prevalence in the population. JAMA Neurol 2019;Epub ahead of print. doi: 10.1001/jamaneurol.2019.0006.

[3] Nieuwkamp DJ, Setz LE, Algra A, Linn FH, de Rooij NK, Rinkel GJ. Changes in case fatality of aneurysmal subarachnoid haemorrhage over time, according to age, sex, and region: a meta-analysis. Lancet Neurol 2009;8:635-42.

[4] Pinnamaneni S, Dutta T, Melcer J, Aronow WS. Neurogenic stress cardiomyopathy associated with subarachnoid hemorrhage. Future cardiol 2015;11(1):77-87.

[5] Guglin M, Novotorova I. Neurogenic stunned myocardium and Takotsubo cardiomyopathy are the same syndrome: a pooled analysis. Congest Heart Fail 2011;17(3):127-32.

[6] Lee VH, Oh JK, Mulvagh SL, Wijdicks EF. Mechanisms in neurogenic stress cardiomyopathy after aneurysmal subarachnoid hemorrhage. Neurocrit Care 2006;5(3):243-9.

[7] Ranieri M, Finsterer J, Bedini G, Parati EA, Bersano A. Takotsubo syndrome: clinical features, pathogenesis, treatment, and relationship with cerebrovascular diseases. Curr Neurol Neurosci Rep 2018;18(5):20.

[8] Ancona F, Bertoldi LF, Ruggieri F, Cerri M, Magnoni M, Beretta L, Cianflone D, Camici PG. Takotsubo cardiomyopathy and neurogenic stunned myocardium: similar albeit different. Eur Heart J 2016;37(37):2830-2.

[9] Kono T, Morita H, Kuroiwa T, Onaka H, Takatsuka $\mathrm{H}$, Fujiwara A. Left ventricular wall motion abnormalities in patients with subarachnoid hemorrhage: neurogenic stunned myocardium. J Am Coll Cardiol 1994;24(3):636-40.
[10] Norberg E, Odenstedt-Herges H, Rydenhag B, Oras J. Impact of acute cardiac complications after subarachnoid hemorrhage on long-term mortality and cardiovascular events. Neurocrit Care 2018;29(3):404-12.

[11] Benarroch EE. The central autonomic network: functional organization, dysfunction, and perspective. Mayo Clin Proc 1993;68:988-1001.

[12] Elgendy AY, Elgendy IY, Mansoor H, Mahmoud AN. Clinical presentations and outcomes of Takotsubo syndrome in the setting of of subarachnoid hemorrhage: a systematic review and meta-analysis. Eur Heart J Acute Cardiovasc Care 2018;7(3):236-45.

[13] Ropper AH. Acute autonomic emergencies and autonomic storm. In: Low PA, editor. Clinical Autonomic Disorders. Boston: Little, Brown, 1993: 747-60.

[14] Talman WT. Cardiovascular regulation and lesions of the central nervous system. Ann Neurol 1985;18:1-12.

[15] Brouwers PJ, Wijdicks EF, Hasan D, Vermeulen M, Wever EF, Frericks H, van Gijn J. Serial electrocardiographic recording in aneurysmal subarachnoid hemorrhage. Stroke 1989;20(9):1162-7.

[16] Talahma N, Alkhachroum AM, Alyahya M, Manjila S, Xiong W. Takotsubo cardiomyopathy in aneurysmal subarachnoid hemorrhage: institutional experience and literature review. Clin Neurol Neurosurg 2016;141:6570.

[17] Kadooka K, Hadeishi H, Kadooka K. Delayed normalization of electrocardiograms in patients with Takotsubo cardiomyopathy due to aneurysmal subarachnoid hemorrhage. World Neurosurg 2017;100:467-73.

[18] Kilbourn KJ, Ching G, Silverman DI, McCullough L, Brown RJ. Clinical outcomes after neurogenic stress induced cardiomyopathy in aneurysmal sub-arachnoid hemorrhage: a prospective cohort study. Clin Neurol Neurosurg 2015;128:4-9.

[19] Kilbourn KJ, Levy S, Staff I, Kureshi I, McCullough L. Clinical characteristics and outcomes of neurogenic stress cardiomyopathy in aneurysmal subarachnoid hemorrhage. Clin Neurol Neurosurg 2013;115(7):909-14.

[20] Moussouttas M, Mearns E, Walters A, DeCaro M. Plasma catecholamine profile of subarachnoid hemorrhage patients with neurogenic cardiomyopathy. Cerebrovasc Dis Extra 2015;5(2):57-67.

[21] Doshi R, Neil-Dwyer G. A clinicopathological study of patients following a subarachnoid hemorrhage. J Neurosurg 1980;52:295-301.

[22] Connor RC. Myocardial damage secondary to brain lesions. Am Heart J 1969;78(2):145-8.

[23] Ripoll JG, Blackshear JL, Diaz-Gomez JL. Acute cardiac complications in critical brain disease. Neurosurg Clin N Am 2018;29:281-97.

[24] Karch SB, Billingham ME. Myocardial contraction bands revisited. Am Heart J 1986;17(1):9-13.

[25] Kajstura J, Cheng W, Reiss K, Clark WA, Sonnenblick EH, Krajewski S, Reed JC, Olivetti G, Anversa P. Apoptotic and necrotic myocyte cell deaths are independent contributing variables of infarct size in rats. Lab Invest 1996;74:86-107.

[26] Konstantinidis K, Whelan RS, Kitsis RN. Mechanisms of cell death in heart disease. Arterioscler Thromb Vasc Biol 2012;32(7):1552-62.

[27] Masuda T, Sato K, Yamamoto S, Matsuyama N, Shimohama T, Matsunaga A, Obuchi S, Shiba Y, Shimizu S, Izumi T. Sympathetic nervous activity and myocardial damage immediately after subarachnoid hemorrhage in a unique animal model. Stroke 2002;33:1671-6.

[28] Novitzky D, Wicomb WN, Cooper DKC, Rose AG, Reichart B. Prevention of myocardial injury during brain 
death by total cardiac sympathectomy in the Chacma baboon. Ann Thorac Surg 1986;41(5):520-4.

[29] Elikowski W, Malek-Elikowska M, Kudlinski B, Skrzywanek P, Smol S, Rzymski S. ECG pattern in reverse Takotsubo cardiomyopathy demonstrated in 5 cases with intracranial hemorrhage. Pol Merkur Lekarski 2016;41(243):136-40.

[30] Mayer SA, LiMandri G, Sherman D, Lennihan L, Fink ME, Solomon RA, DiTullio M, Klebanoff LM, Beckford AR, Homma S. Electrocardiographic markers of abnormal left ventricular wall motion in acute subarachnoid hemorrhage. J Neurosurg 1995;83(5):889-96.

[31] Sommargren CE, Zaroff JG, Banki N, Drew BJ. Electrocardiographic repolarization abnormalities in subarachnoid hemorrhage. J Electrocardiol 2002;35:257-62.

[32] Chatterjee S. ECG changes in subarachnoid haemorrhage: a synopsis. Neth Heart J 2011;19(1):31-4.

[33] Ahmadian A, Mizzi A, Banasiak M, Downes K, Camporesi EM, Thompson Sullebarger J, Vasan R, Mangar D, van Loveren HR, Agazzi S. Cardiac manifestations of subarachnoid hemorrhage. Heart Lung Vessel 2013;5(3):168-78.

[34] Jeong YS, Kim HD. Clinically significant cardiac arrhythmia in patients with aneurysmal subarachnoid hemorrhage. J Cerebrovasc Endovasc Neurosurg 2012;14(2):904.

[35] Andreoli A, di Pasquale G, Pinelli G, Grazi P, Tognetti F, Testa C. Subarachnoid hemorrhage: frequency and severity of cardiac arrhythmias. A survey of 70 cases studied in the acute phase. Stroke 1987;18(3):558-64.

[36] Frontera JA, Parra A, Shimbo D, Fernandez A, Schmidt JM, Peter P, Claassen J, Wartenberg KE, Rincon F, Badjatia N, Naidech A, Connolly ES, Mayer SA. Cardiac arrhythmias after subarachnoid hemorrhage: risk factors and impact on outcome. Cerebrovasc Dis 2008;26(1):71-8.

[37] Amin H, Aronow WS, Lleva p, McClung JA, Desai H, Gandhi K, Marks S, Singh B. Prevalence of transthoracic echocardiographic abnormalities in patients with ischemic stroke, intracerebral hemorrhage, and subarachnoid hemorrhage. Arch Med Sci 2010;6(1):40-2.

[38] Yolas C, Kanat A, Aydin MD, Altas E, Kanat IF, Kazdal H, Duman A, Gundogdu B, Gursan N. Unraveling of the effect of nodose ganglion degeneration on the coronary artery vasospasm after subarachnoid hemorrhage: an experimental study. World Neurosurg 2016;86:79-87.

[39] van der Bilt IA, Hasan D, Vandertop WP, Wilde AA, Algra A, Visser FC, Rinkel GJ. Impact of cardiac complications on outcome after subarachnoid hemorrhage: a meta-analysis. Neurology 2009;72(7):635-42.

[40] Katrukha IA. Human cardiac troponin complex. Structure and functions. Biochemistry (mosc) 2013;78:1447-65.

[41] Parekh N, Venkatesh B, Cross D, Leditschke A, Atherton J, Miles $\mathrm{W}$ et al. Cardiac troponin I predicts myocardial dysfunction in aneurysmal subarachnoid hemorrhage. J Am Coll Cardiol 2000;36:1328-35.

[42] Sandhu R, Aronow WS, Rajdev A, Sukhija R, Amin H, $\mathrm{D}^{\prime}$ Aquila K et al. Relation of cardiac troponin I levels with in-hospital mortality in patients with ischemic stroke, intracerebral hemorrhage, and subarachnoid hemorrhage. Am J Cardiol 2008;102(5):632-4.

[43] Tanabe M, Crago EA, Suffoletto MS, Hravnak M, Frangiskakis JM, Kassam AB. Relation of elevation in cardiac troponin I to clinical severity, cardiac dysfunction, and pulmonary congestion in patients with subarachnoid hemorrhage. Am J Cardiol 2008;102(11):1545-50.

[44] Naidech AM, Kreiter KT, Janjua N, Ostapkovich ND, Parra $\mathrm{A}$, Commichau $\mathrm{C}$ et al. Cardiac troponin elevation, cardiovascular morbidity, and outcome after subarachnoid hemorrhage. Circulation 2005;112:2851-6.
[45] Oras J, Grivans C, Dalla K, Omerovic E, Rydenhag B, Ricksten SE et al. High-sensitive troponin $\mathrm{T}$ and $\mathrm{N}$-terminal pro B-type natriuretic peptide for early detection of stress-induced cardiomyopathy in patients with subarachnoid hemorrhage. Neurocrit Care 2015;23:233-42.

[46] M Bay, V Kirk, J Parner, C Hassager, H Nielsen, K Krogsgaard et al. NT-proBNP: a new diagnostic screening tool to differentiate between patients with normal and reduced left ventricular systolic function. Heart 2003;89(2):150-4.

[47] Tung PP, Olmsted E, Kopelnik A, Banki NM, Drew BJ, Ko $\mathrm{N}$ et al. Plasma B-type natriuretic peptide levels are associated with early cardiac dysfunction after subarachnoid hemorrhage. Stroke 2005;36:1567-9.

[48] Banki N, Kopelnik A, Tung P, Lawton MT, Gress D, Drew B et al. Prospective analysis of prevalence, distribution, and rate of recovery of left ventricular systolic dysfunction in patients with subarachnoid hemorrhage. J Neurosurg 2006;105:15-20.

[49] Keiko S, Eiichi W, Akira Y, Masatsugu I, Hirotoshi S, Hitoshi $\mathrm{H}$ et al. Prognostic implications of left ventricular wall motion abnormalities associated with subarachnoid hemorrhage. Int Heart J 2008;49:75-85.

[50] Kopelnik A, Fisher L, Miss JC, Banki N, Tung P, Lawton MT et al. Prevalence and implications of diastolic dysfunction after subarachnoid hemorrhage. Neurocrit Care 2005;3:132-8.

[51] Bihorac A, Ozrazgat-Baslanti T, Mahanna E, Malik S, White $\mathrm{P}$, Sorensen $\mathrm{M}$ et al. Long-term outcomes for different forms of stress cardiomyopathy after surgical treatment for subarachnoid hemorrhage. Anesth Analg 2016;122:1594-602.

[52] Diringer MN, Bleck TP, Claude Hemphill J, Menon D, Shutter L, Vespa P, et al. Critical care management of patients following aneurysmal subarachnoid hemorrhage: recommendations from the Neurocritical Care Society's Multidisciplinary Consensus Conference. Neurocrit Care 2011;15:211-40.

[53] Madhavan M, Borlaug BA, Lerman A, Rihal CS, Prasad A. Stress hormone and circulating biomarker profile of apical ballooning syndrome (Takotsubo cardiomyopathy): insights into the clinical significance of B-type natriuretic peptide and troponin levels. Heart 2009;95:1436-41.

[54] Templin C, Ghadri JR, Diekmann J, Napp LC, Bataiosu $\mathrm{DR}$, Jaguszewski $\mathrm{M}$, et al. Clinical features and outcomes of Takotsubo (stress) cardiomyopathy. N Engl J Med 2015;373:929-38.

[55] Citro R, Rigo F, D'Andrea A, Ciampi Q, Parodi G, Provenza G, et al. Echocardiographic correlates of acute heart failure, cardiogenic shock, and in-hospital mortality in tako-tsubo cardiomyopathy. JACC Cardiovasc Imaging 2014;7:119-29.

[56] Kerro A, Woods T, Chang JJ. Neurogenic stunned myocardium in subarachnoid hemorrhage. J Crit Care 2017;38:27-34.

[57] Malik AN, Gross BA, Rosalind Lai PM, Moses ZB, Du R. Neurogenic stress cardiomyopathy after aneurysmal subarachnoid hemorrhage. World Neurosurg 2015;83:880-5.

[58] Mazzeo AT, Micalizzi A, Mascia L, Scicolone A, Siracusano L. Brain-heart crosstalk: the many faces of stress-related cardiomyopathy syndromes in anaesthesia and intensive care. Br J Anaesth 2014;112:803-15.

[59] Cruickshank JM, Neil-Dwyer G, Hayes Y, Degaute JP, Kuurne T, Kytta J, et al. Stress/catecholamine-induced cardiac necrosis. Reduction by beta 1-selective blockade. Postgrad Med 1988;Spec No:140-7.

[60] Liang CW, Chen R, Macri E, Naval N. Preadmission beta-blockers are associated with decreased incidence of neurogenic stunned myocardium in aneurys- 
mal subarachnoid hemorrhage. J Stroke Cerebrovasc Dis 2013;22:601-7.

[61] Cereda C, Ghika J, Maeder P, Bogousslavsky J. Strokes restricted to the insular cortex. Neurology 2002;59:19505.

[62] Kumar S, Kaushik S, Nautiyal A, Choudhary SK, Kayastha $\mathrm{BL}$, Mostow $\mathrm{N}$, et al. Cardiac rupture in Takotsubo cardiomyopathy: a systematic review. Clin Cardiol 2011;34:672-6.

[63] Vriz O, Brosolo G, Martina S, Pertoldi F, Citro R, Mos $\mathrm{L}$, et al. In-hospital and long-term mortality in Takotsubo cardiomyopathy: a community hospital experience. J Community Hosp Intern Med Perspect 2016;6:31082.

[64] Taccone FS, Brasseur A, Vincent J-L, De Backer D. Levosimendan for the treatment of subarachnoid hemorrhage-related cardiogenic shock. Intensive Care Med 2013;39:1497-8.

[65] Elesber AA, Prasad A, Lennon RJ, Wright RS, Lerman A, Rihal CS. Four-year recurrence rate and prognosis of the apical ballooning syndrome. J Am Coll Cardiol 2007;50:448-52.
[66] Al-Mufti F, Morris N, Lahiri S, Roth W, Witsch J, Machado I, et al. Use of intra-aortic-balloon pump counterpulsation in patients with symptomatic vasospasm following subarachnoid hemorrhage and neurogenic stress cardiomyopathy. J Vasc Interv Neurol 2016;9:28-34.

[67] Gopinath R, Ayya S. Neurogenic stress cardiomyopathy: what do we need to know. Ann Card Anaesth 2018;21:228.

[68] Vriz O, Brosolo G, Martina S, Pertoldi F, Citro R, Mos L et al. In-hospital and long-term mortality in Takotsubo cardiomyopathy: a community hospital experience. J Community Hosp Intern Med Perspect 2016;6(3).

[69] Lee VH, Connolly HM, Fulgham JR, Manno EM, Brown RD, Wijdicks EFM. Tako-tsubo cardiomyopathy in aneurysmal subarachnoid hemorrhage: an underappreciated ventricular dysfunction. J Neurosurg 2006;105:264-70.

[70] Song BG, Park S-J, Noh HJ, Jo HC, Choi J-O, Lee S-C, et al. Clinical characteristics, and laboratory and echocardiographic findings in Takotsubo cardiomyopathy presenting as cardiogenic shock. J Crit Care 2010;25:329-35. 